qualified in 1866 with a thesis on the anatomical lesions in general paralysis. The following year he was appointed physician to the Asile Sainte-Anne, to which he was attached for forty-five years. His most important work was concerned with the psy. choses produced by alcoholism, in the modern investigation of which he was a pioneer, absinthe, in the prohibition of which in France he was mainly instrumental, and morphia; epilepsy, and sexual anomalies and aberrations. As director of SainteAnne, where he founded the Société clinique de médecine mentale, he was an enthusiastic advocate of the no restraint system and especially of the suppression of the straight-jacket. His clinical lectures, which attracted numerous French and foreign physicians to Sainte-Anne, were for thirty years published in Le Progrès Médical, of which the issue for June 8 commemorates the centenary. In 1893 he was elected a member of the French Academy of Medicine, of which he became president in 1915. In his will he left the sum of 25,000 francs to the Academy for the foundation of a prize in psychiatry which bears his name. His death took place on September 27, 1916, when he had reached the age of eighty-one years, his faculties remaining intact until the end.

\section{Basutoland in Transition}

Fundamental changes in the life and economy of the natives of Basutoland are foreshadowed by the report (Cmd. 4907. H.M. Stationery Office) of the Commission, of which Sir Alan Pim is chairman, appointed by the Secretary of the Dominions to inquire into the financial and economic position of the country. The recommendations are drastic and affect almost every aspect of native life. The gravity of the financial situation, which dictated the appointment of the Committee in the first instance, shows no sign of alleviation, and even in the improb. able contingency that the proposals are entirely set aside, the force of circumstances alone, it would seem, will bring about disastrous changes which will lead to the breakdown of native culture and the system of administration. The spirit of independence and pride of race characteristic of the Basuto people should be preserved at all costs as the essential condition of their future progress. Their spirit is explicitly recognised in the Report as a dominant factor in the problem of reform ; but it is pointed out that, unless rightly directed, it may prove an obstacle in the way of advance towards the goal the Commission has in view - the creation of a real system of 'indirect rule'. In the multiplicity of topics discussed and of ameliorative measures suggested, this is the major issue. While the financial situation of the Protectorate has undoubtedly complicated its political future, the internal situation and the formulation of a settled administrative policy which will afford opportunity for the development and utilisation of the admittedly favourable traits in native character and culture must obviously be a prior consideration to that of the eventual transfer of responsibility to the Union of South Africa.

\section{R.A.F. Big Flying Boat}

THe performance figures of the Saraband built by Short Brothers of Rochester for the R.A.F., just divulged for the first time although the machine was built in 1932, show that it is by far the largest flying boat in the R.A.F. equipment, and is more powerful than even the German D.O.X. Its engines total 5,500 horse-power, maximum speed 150 miles an hour, climb $750 \mathrm{ft}$. a minute, with an air range of 1,450 miles, with full load. In this respect it is worth remembering that many countries make a practice of reporting performance trials with specially light. ened loads. The machine has a wing span of $120 \mathrm{ft}$. and is $90 \mathrm{ft}$. long. It carries a military load of 5,960 lb., which includes an automatic pilot, the usual machine guns, and a $1 \frac{1}{2}$ in. automatic quick firer. The hull is a self-contained unit, containing sleeping accommodation for the crew, a workshop, a ward room, a drying compartment, an anchor winch, and gear for changing engines afloat. It is built entirely of steel and duralumin, and the hull design incorporates many novel structural features. A civil flying boat of the same size was under construction at the same time, but was stopped for reasons of economy.

\section{Presentation of Prof. Piccard's Gondola to the Science Museum}

ON June 12, the gondola of the balloon in which Prof. A. Piccard and M. Max Cosyns ascended into the stratosphere on August 18, 1932, was presented to the Science Museum, South Kensington, by M. Jean Willems, director of the Fonds National de la Recherche Scientifique, Brussels. His Excellency the Belgian Ambassador presided, and both Prof. Piccard and M. Cosyns were present. The gondola consists of an air-tight sphere (about 2 metres in diameter) of aluminium alloy, fitted with two manholes and several portholes, and equipped with various scientific instruments; it was attached to the hydrogen-filled balloon with which Prof. Piccard made his previous ascent on May 27, 1931. The second ascent, in 1932, was made from Dübendorf Aerodrome, near Zurich, and after a twelve-hour flight, the balloon landed safely in a field at Cavallaro di Monzambano, about ten miles south of Lake Garda. The maximum height reached during the voyage (determined trigonometrically) was 16,940 metres (10 $\frac{1}{2}$ miles). The main objective of the flight was the investigation of cosmic radiations. Observations were made to ascertain the variation of intensity of these rays with height, and the distribution of the radiation in different directions was studied by means of a tubular Geiger counter.

\section{Early Design for an Aeroplane}

The Science Museum, South Kensington, has just acquired through the generosity of Mr. P. A. Smith of Scarborough a small disc of silver about an inch in diameter bearing an engraved design for a flying machine which is remarkable in conception. The disc bears the initials 'G.C.' with the letter ' $R$ ' beneath and it is dated 1799 . The reverse contains a diagram of forces relative to the design illustrated. 
There is little doubt that it is the work of Sir George Cayley, Bart. (1774-1857), who was the first to attempt to explain mathematically the fundamental principles of mechanical flight. The flying machine represented is a manually propelled (assisted) glider. It is a large monoplane, the plane being curved, with the operator sitting in a boat-shaped structure below and working by means of levers two large rectangular oars or paddles which were probably intended to function on the non-return valve principle by means of flaps. An interesting feature is the combined rudder and elevator arrangement which consists of surfaces fixed at right angles to one another, the whole, it appears, universally pivoted-a device which has been attributed to Alphonse Penaud at a much later date. Research is being undertaken to discover the full significance of the design, but the disc has been placed on exhibition.

\section{The National Physical Laboratory}

THE report of the Laboratory for the year 1934 is a well-illustrated and indexed quarto volume of 260 pages. Each of the eight departments of the Labora. tory gives a short account of its principal activities in an interesting and thoroughly readable form. The increase in activity in industry has produced a corresponding increase in the work carried out by the Laboratory, particularly in that relating to shipbuilding, and it has been necessary to call for overtime and to increase the staff. The movement for the abatement of noise has resulted in demands on the Sound Department from the Ministries of Health and of Transport. The deaths of Sir Arthur Schuster, Sir Horace Lamb, Sir Alfred Ewing and Dr. W. Rosenhain have deprived the Laboratory of four of its friends and supporters, but the changes of staff have been slight. The lectures on the work of the Laboratory given at a number of provincial centres have been much appreciated, and are to be continued. The new buildings for photometry will probably be brought into use this year, new high-speed wind tunnels are already in operation and the Lithgow installation for testing propeller blades will be available next year. The comparison of standards of measurement of all kinds with those of other countries has been continued with satisfactory results. The sound-isolating properties of walls and partitions of many types have been investigated and field tests of actual buildings can now be carried out. The work on refrigeration and preservation of food of all kinds has been continued for the Food Investigation Board, and that on protection from and dosage of $\mathrm{X}$-rays and radium, for the Medical Research Council. The lubricating value of the oils derived from the distillation of coal is being investigated, and the production and working of the extremely light alloys of magnesium are being tested. Rapid advances are being made in our knowledge of the structure of the ionosphere, on which so many of the phenomena of wireless communication depend.

\section{The Grand Coulee Dam}

The Columbia River in the United States is second in size only to the Mississippi. Owing to the fact that its source is high in a region of melting snows in the mountains of western Canada and Montana, its discharge is more continuous than that of all the arid regions of the west and the middle west combined. In an article in the Scientific American of April, Grace Kirkpatrick gives an interesting account of the Grand Coulee (Grand Valley) dam which engineers are now busily constructing. In prehistoric times the Columbia River, then much larger than it is to-day, was dammed by a glacier, and the torrents of water which poured through the high cliffs bordering the river flowed down and formed the Grand Coulee. The walls of the valley are in some places 1,000 feet high. The upper 20 miles of the river are being closed with dams at each end to form a huge reservoir. The Columbia River sweeps across the State of Washington and forms for many miles the border between Washington. and Oregon. On the plateau above its canyon-like banks are millions of arid acres known as the Columbia Basin which if suitably irrigated would be one of the most fertile lands in the world. The dam is being built in two units - the high dam and the low dam. The latter is exclusively a power development while the high dam will be used for power, irrigation, storage and navigation development. The dam will raise the waters of the Columbia so that they can be pumped into the reservoir of the Grand Coulee and will then flow over the parcned acres of the Columbia Basin. The blocking of the river will create the largest artificial lake in the world. It is $\mathbf{1 5 1}$ miles long and will extend into Canada. The spillway in the centre of the high dam will be 1,800 feet long and no less than 325 feet high.

\section{Costs of Electric Lighting since rgro}

THE lowering of the cost of the electric light during the last twenty-five years, mainly due to scientific research and improved engineering methods, is fully appreciated by few. In 1910, carbon filament lamps, which had held the foremost place since the inception of the incandescent lamp, were rapidly being replaced by tantalum and tungsten lamps giving almost twice as much light for the same electric power. In the same year, by means of the new 'squirted' filament lamp, the light-giving efficiency was more than doubled. In 1912 the drawn tungsten filament nearly trebled the efficiency. All these lamps.were vacuum lamps. In 1916 the invention of the gas-filled lamp trebled the efficiency, and the latest type of gasfilled lamp, the 'coiled coil' lamp, has nearly quadrupled the light efficiency, giving 11.25 lumens (approximately 0.9 candle) per watt. Many consumers are now getting their electric light at a cost of $0.5 d$. per unit who had to pay $6 d$. or more per unit in 1910. Electrical engineers and scientific workers may well be proud of lowering the cost to one fiftieth of what it was in 1910 .

\section{Metallurgical Research}

THE lecture given by Dr. H. Moore, director of the British Non-Ferrous Metals Research Association, before the London Section of the Institute of Metals 